\title{
Flexible application of Lean Thinking in Mass Customization Technological Innovation system
}

\author{
Tian-ming $\mathrm{Xiao}^{1,2}$, Aihua $\mathrm{Wu}{ }^{1}$ \\ ${ }^{1}$ Fujian University of Technology, Fujian Fuzhou China 350108; \\ ${ }^{2}$ Chongqing University, Chongqing China 400045 \\ xtm-9@163.com
}

Keywords: Lean Thinking. Mass Customization. Technology Innovation.

Abstract. It is important to research on how to improve the technological innovation system of the enterprises for Mass Customization by scientific theory. Based on the analysis of Lean Thinking, the advantage of the flexible application of Lean Thinking in Mass Customization enterprises' technological innovation system is analyzed. Further, the key to improve Mass Customization enterprises' technological innovation system by the flexible application of Lean Thinking are put forward.

\section{Introduction}

Mass Customization is a new type of enterprise production and management mode after about a century of Mass Production mode. ${ }^{[1-2]}$ Mass customization is the mass production of customized products and services. Mass Customization translates the customized product production problems into mass production problems through product restructuring and process reengineering. Mass Customization combines the advantages of mass production and customized production using modern information technology, flexible manufacturing technology and so on. Mass customization combine the strategic advantages of "low cost" and "customization". Mass Customization can produce any number of products with the cost and speed of mass production for individual customers or small batch and multi variety market. ${ }^{[3-5]}$ With the personalization and change of consumers' demands, the market is highly fragmented and rapidly changing, and the traditional Mass Production mode is not adaptive. Mass Customization mode is born to comply with the call of the times. Mass Customization mode is becoming the dominated production mode in the new economic era replaceing traditional Mass Production mode. ${ }^{[6]}$ In the face of changing market and demanding consumers, all enterprises must attach great importance to the continuous technological innovation. It is necessary to research on how to improve the technology innovation management of enterprises for Mass Customization.

The application of scientific theory to improve the enterprises' independent innovation system has important theoretical and practical significance. scientific theory concluding scientific thinking mode and scientific mothods and tools, which is the source of inspiration for all kinds of enterprises' technological innovation. Only by using scientific theory, enterprises' technological innovation can be effective.

Lean Thinking concluding scientific Lean thinking mode and scientific Lean mothods and tools, which has been widely recognized and applied because of its "low cost, zero defects, continuous improvement" and other aspects of outstanding contribution.The flexible application of Lean Thinking in the enterprises' technological innovation system for Mass Customization will effectively improve the speed, the scientific and the quality of the enterprises' technological innovation, and effectively reduce the cost of technological innovation. 


\section{The basic principles and basic ideas of Lean Thinking}

In the fall of 1996, James P.Womack and Daniel T.Jones published their book named "Lean Thinking". James P.Womack and Daniel T.Jones points out that Lean Thinking has five basic principles. The first basic principle is to redefine the value of products or services according to the needs of customers combining with the actual situation of enterprises. The second basic principle is to identify the value stream of the whole process for the product or the service. The third basic principle is to keep the value activities which can creat value flow uninterrupted. The fourth basic principle is to pull the value flow of the enterprises rely on the customer's needs. The fifth basic principle is to improve continuously and keep the pursuit of perfection for always. ${ }^{[7]}$ On this basis, we further analyze the profound connotation of Lean Thinking.

1. The core goal of Lean Thinking is to eliminate all waste

The five basic principles of Lean Thinking are all reflected in the core goal that is to eliminate all waste . Lean Thinking is a powerful weapon to eliminate waste. Lean Thinking can be applied to identify and eliminate all waste which can be avoided by the existing production conditions and technology through a series of scientific procedures and tools. Lean Thinking reenact enterprise activities, and

make the retained and valuable activities into continuous flow for improvement according to the optimal order in customer demand with low energy consumption and high efficiency. Lean Thinking can save the manpower, material resources, funds, time, space and other resources to the maximum degree.A economics professor in University of Tokyo pointed out that it should be affirmed that the core idea of Lean Thinking is to eliminate waste. ${ }^{\text {"[8] }}$

2. The value orientation of Lean Thinking is to take the customer as the center

Lean Thinking is essentially a set of systematic theory and practical guidelines for the pursuit of minimal waste and maximum customer satisfaction Customer satisfaction is the embodiment of product value.The product value and enterprise value can be raised only by improving customer satisfaction. Customers' demands are the core for Lean Thinking to define value, identify the value stream and pull the value stream. Lean enterprises should firstly consider the problems that are how to adapt to the real needs of customers, how to unify the enterprises' interests and customers' demands, and so on . All of the value of the product is reflected in the realization of the final customers' demands.

3. Lean thinking is the continuous pursu of the perfect

James P.Womack has repeatedly stressed that Lean Thinking is to create the perfect value for the users by the perfect process. Lean Thinking's quest for perfection is relentless. Lean Thinking is not only keep the pursuit of "zero waste, low cost", but also keep the pursuit of "zero fault", "zero defect", "high efficiency", "high customer satisfaction", and so on. Lean Thinking pulls the value stream of products or servicesto the perfect state in the spirit of continuous improvement during the process of pursuing its core objectives.

4. Scientific nature and systematic nature are the sucessful guarantee of Lean Thinking ${ }^{[9]}$

Lean Thinking uses a series of scientific and systematic theory, methods and tools to ensure the successful practice of Lean. For example, Lean Thinking greatly improves the work efficiency,value,quality and customer satisfaction through the application of Kanban Management, Standardized Operation, Concurrent Engineering Mamagement, Last Planner System, Value Engineering Mamagemen Total Quality Management, Quality improvement, Total Production Maintenance, 5S, Team Work, JIT, Rolling Plan Method and so on.

\section{The advantages of the flexible application of Lean Thinking in Mass Customization enterprises' technological innovation}

Lean Thinking can not only reduce the cost of technological innovation in Mass Customization enterprises, but also improve the comprehensive ability of Mass Customization enterprise technological innovation from many aspects . 
1. Greatly reduce the cost of technological innovation in Mass Customization enterprises

Lean Thinking,which has the core goal of "eliminate all waste". The basic principles, techniques, tools and methods of Lean Thinking are all aimed at waste. The most waste on the technological innovation chain, production chain, management chain, logistics chain in Mass Customization enterprises will be eliminated by the flexible application of Lean Thinking in Mass Customization enterprises. The technology innovation, technological development and technological application with low cost will be realized.

2.Improve the comprehensive ability of the enterprises' technological innovation for Mass Customization

The flexible application of Lean Thinking in the enterprises' technological innovation for Mass Customization is to make the basic principles and ideas of Lean Thinking get a penetration into the enterprises' technological innovation system for Mass Customization, and the basic mothods of Lean Thinking can be flexibly used in the enterprises' technological innovation system for Mass Customization according to the actual situation of the enterprises. Lean Thinking is fully integrated with the ability of Mass Customization mode to use the modern information technology, flexible manufacturing technology, product restructuring, process reengineering, etc. With the flexible application of Lean concepts and tools in Mass Customization enterprise technological innovation system, the quality of technological innovation, the efficiency of technological innovation, staff technological innovation initiative, the ability to solve technological innovation difficulties, and the customer environment of technological innovation will be improved. At the same time, the technological innovation system of Mass Customization enterprises get continuous improvement with the perfection consciousness of Lean Thinking.

\section{The key to improve Mass Customization enterprises' technological innovation system by the flexible application of Lean Thinking}

It is the most important key point for improving Mass Customization enterprises' technological innovation system by the flexible application of Lean Thinking that is to be dynamic and adaptable according to the enterprises' objective reality and needs. In addition, the following three key points should be emphasized.

\section{Build Lean Enterprise Culture}

Enterprise culture is the "invisible rule" and enterprise atmosphere that permeates the whole enterprise. Enterprise culture is closely related to the technological innovation ability of enterprises. Inactive enterprise culture will restrain employees from the whole of enthusiasm and creativity and become a great obstacle to enterprise's technological innovation. Lean enterprise culture is a kind of enterprise culture which emphasizes scientific and systematic perfection. Lean enterprise culture can not only effectively promote the enthusiasm of employee's technology innovation, but also help employees to overcome various difficulties in the process of technological innovation. Lean enterprise culture can provide a good environment for enterprises' technological innovation.

Building Lean Enterprise Culture is the result of flexible application of Lean concepts. The managers of Enterprises should study Lean Thinking firstly. The managers should promote the staff study Lean Thinking through training, publicity, building lean system, etc. In order to formed Lean culture atmosphere which is full of the whole enterprise, the managers should do their best to make Lean concepts penetrate into all aspects of Mass customization enterprises' technological innovation system.

\section{To use Lean methods and tools flexibly}

Lean methods and tools have been proved scientific and effective by a lot of successful practices. During the process of the technological innovation inMass Customization enterprises, the flexible application of Lean methods and tools can effectively improve the quality, efficiency, value and customer satisfaction while the cost of technological innovation is reduced. 
Lean thinking includes a series of scientific methods and tools. We should use Lean methods and tools flexibly according to the objective situation and the real goal of various aspect during the process of Mass Customization enterprises' technological innovation. For example, in order to improve the reliability of the plans and achieves optimal control,we can apply Last Planner System and Rolling Planning method of Lean Thinking flexibly.In order to find and eliminate the waste which is hidden in each link of the enterprises' technological innovation and difficult to be found,we can apply the value flow chart of Lean Thinking. In order to achieve the most streamlined and optimized technological innovation process, we can apply process management method of Lean Thinking flexibly. In order to achieve the best technological innovation team which achieve the best cooperation,we can apply Team Work method of Lean Thinking flexibly. In order to shorten the innovation cycle and achieve a reasonable lap of technological innovation, we can apply Concurrent Engineering method of Lean Thinking.In order to feedback rapidly the needs of all sectors of the technological innovation and improve the efficiency of technological innovation, we can apply JIT, Kanban management method of Lean Thinking flexibly. In order to improve the value of technological innovation and improve the customer satisfaction of technological innovation, we can apply the value engineering method of Lean Thinking flexibly. In order to improve the scientific nature and efficiency of Mass Customization Enterprises' technological innovation, we can apply the standard operation method of Lean Thinking flexibly.In order to improve the quality of Mass Customization Enterprises' technological innovation,we can apply Total Quality Management,Quality Housing, Quality Improvement, 5S and other theoretical methods of Lean Thinking flexibly.

3. Customer demand pull technological innovation

Lean Thinking is not only take the customers' demands as the center, but also emphasis on pulling thinking. Mass customization enterprises should be able to meet the needs of customers to the Maximum degree. In order to meet the needs of customers to the Maximum degree and improve the competitive advantages of Mass Customization enterprises, all technological innovation of Mass Customization enterprises should be driven by customers' demands.

It is very important to understand the customers' demands fully. Enterprises need to maintain close contact with customers. On the one hand, Mass Customization enterprises should guide customers to understand the enterprises' products or services through diversified forms. The customers' particular demands for specific products or services can be expressed by means of customization. On the other hand, Mass Customization enterprises should closely follow the pace of customers

' needs and try their best to meet the needs of customers. The customer's new demands should be taken as the driving source of Mass Customization enterprises' sustainable innovation.

In fact, maintaining customers' demand as a driving source of enterprises' technological innovation can help Mass Customization enterprises to maximize the elimination of waste. First of all, any technical innovation betray customers' demands is worthless, which belongs to the waste. Any enterprise must eliminate waste. Secondly, the puller of the enterprises' technological innovation value flow should be the downstream customers. The final customers of any technological innovation are the final definition of the product value. Only the technological innovation pulled by the needs of customers is valuable, which can eliminate the excess consumption and the waste of backlog.

\section{Conclusions}

In the new economic era, Mass Customization mode which has become the dominant production mode has gradually replaced the traditional Mass Production mode.As other enterprises, technological innovation is also an important support for the existence and sustainable development of Mass Customization enterprises. It is a subject worthy of study that is how to scientifically improve the technological innovation system of Mass Customization enterprises.It is suggested that Mass Customization enterprises' technological innovation system should apply Lean Thinking 
flexibly.Three key points, which are building Lean Enterprise Culture, the flexible application of Lean methods and tools and customer demand pulling technological innovation are focused on as the key of improving Mass Customization enterprises' technological innovation system by the flexible application of Lean Thinking.

\section{Acknowledgements}

This work was financially supported by the National Social Science Project (12BGL015).

\section{References}

[1] Alvin Toffler. Future Shock [M]. New York: Random House, 1970. [2] Davis S. M.. Future Perfect [M]. New York: Addison-Wesley,1987. [3]B. Joseph Pine II. Mass Customization: The New Frontier in Business Competition [M]. Boston: Harvard Business Press, 1993. [4] Davis S. M..From Future Perfect: Mass Customizing[J].Planning Review,1989,17(2):16-21. [5]M.Kay. Making Mass Customization Happen: Lessons for implementation[J].Planning Review,1993,21(4):14-18. [6]Yao Jianming. Supply Chain Scheduling Optimization in Service Mass Customization[J].Operation Research and Management Science, 2015(2):10-18.(in Chinese) [7] James P.Womack, Daniel T.Jones. Lean thinking [M].1996.

[8]James P.Womack,Daniel T.Jones.Lean Thinking [M].America:Oversea Publishing House,2006.

[9]Xiao Tianming.Lean-Flexible Thinking and Lean-Flexible Management_- The Innovation of Thinking and Scientific Management in the New Economic Era[M]. China Economic Publishing House,2012.(in Chinese)

Author brief introduction: Tianming Xiao ( 1973 - ), female, the Han nationality, Fujian University of Technology, professor, Doctoral student of Chongqing University, research on direction for management science.

Aihua Wu(1975-), male, the Han nationality, Fujian University of Technology, lecturer, Master, research on direction for management science. 